https://helda.helsinki.fi

\title{
Investigating Finnish teacher guides as a resource for mathematics teaching
}

\section{Hemmi, Kirsti}

2018

Hemmi , K , Krzywacki , H \& Koljonen , T 2018 , ' Investigating Finnish teacher guides as a resource for mathematics teaching ' , Scandinavian Journal of Educational Research, vol. 62 , no. 6 , pp. $911-928$. https://doi.org/10.1080/00313831.2017.1307278

http://hdl.handle.net/10138/326219

https://doi.org/10.1080/00313831.2017.1307278

unspecified

acceptedVersion

Downloaded from Helda, University of Helsinki institutional repository.

This is an electronic reprint of the original article.

This reprint may differ from the original in pagination and typographic detail.

Please cite the original version. 
The following is a pre-publication version of

Hemmi, K., Krzywacki, H., \& Koljonen, T. (2017). Investigating Finnish Teacher Guides as a Resource for Mathematics Teaching. Scandinavian Journal of Educational Research: 1-18. Published online 08 May 2017, doi.org/10.1080/00313831.2017.1307278

Page numbers will not match those of the published version. 


\author{
Investigating Finnish Teacher Guides as a Resource for Mathematics Teaching \\ Kirsti Hemmi, Heidi Krzywacki ${ }^{\mathrm{a}, \mathrm{d}} \quad$ Tuula Koljonen $^{\mathrm{b}}$ \\ ${ }^{a}$ Faculty of Education and Welfare Studies, Åbo Akademi University, Vasa, Finland, ${ }^{b}$ School of \\ Education, Culture and Communication, Mälardalen University, Västerås, Sweden, ${ }^{c}$ Faculty of \\ Behavioural Sciences, University of Helsinki, Finland, ${ }^{d}$ Department of Education, Uppsala University, \\ Sweden
}

\begin{abstract}
We investigate the most commonly used Finnish mathematics teacher guides (Grades 1-6) as to what kind of resource they constitute for teachers in planning and enacting mathematics teaching and what kind of mathematics classroom they promote. We found the structure and the main contents of the guides quite homogenous. The nature of communication was mostly descriptive, but the separate activities suggested for each lesson were quite explicitly described. Suggested activities, such as mental calculation tasks and homework assignment, were typically motivated by non-specific rationale, and many activities seemed to be taken for granted in the Finnish mathematics classroom culture. The results add both to our knowledge about how to analyse teacher guides and to our knowledge about Finnish educational features.
\end{abstract}

Keywords: mathematics curriculum materials, teacher guides, elementary school, Finland

\title{
Introduction
}

Recent research has focused on the impact curriculum materials have on the quality of mathematics teaching, as they are typically a major resource for planning lessons and school practice (e.g., Jablonka \& Johansson, 2010; Stein \& Kim, 2009; Stylianides, 2007).

Consequently, curriculum materials serve as an important tool for teachers in both enabling and constraining their thoughts and actions (Stein, Remillard, \& Smith, 2007). Teacher guides can also be regarded as a resource for enhancing teachers' professional development (e.g., Ball \& Cohen, 1996; Davis \& Krajcik, 2005; Remillard, 2005; cf. Cobb \& Jackson, 2012). This has shifted the focus from textbook research, which is still the main approach in the field, towards research on curriculum materials, including teacher guides (cf. Fan, Zhu, \& Miao, 2013). Research has produced important information about the interactive relationship between teachers and curriculum materials and shown that mathematics texts can influence teachers' beliefs, knowledge, and classroom practices (cf. Lloyd, 2009).

At the moment, we know very little about the characteristics of curriculum materials in different cultural-educational contexts, although there is a growing interest in this issue in our field (e.g., Kulm \& Li, 2009; Remillard, Steenbrugge, \& Bergqvist, 2014). The present study adds to the knowledge by investigating Finnish teacher guides and their potential from two main perspectives: the content (cf. e.g., Davis \& Krajcik, 2005) and the nature of communication (cf. Remillard \& Reinke, 2012; Brown, 2009) characterizing the material.

We have chosen to investigate Finnish curriculum materials for several reasons. Finland is a country with relatively good learning outcomes in mathematics (e.g. OECD, 2013), and it is fair to claim that Finnish teachers are well-educated professionals with Master's degrees. Moreover, the country has a rather long tradition, since the 1980 s, of producing extensive teacher guides written by teams of teachers and other experts, such as university teacher 
educators in mathematics education (Niemi, 2012). Curriculum materials are widely used as over 90 percent of teachers utilise some material during planning and implementation, especially in elementary mathematics education (Kupari, 1999; see also Pehkonen, Ahtee, \& Lavonen, 2007). Curriculum materials, especially the basis on which to select appropriate materials for teaching mathematics, are also discussed and analysed during research-based teacher education (Krzywacki, Pehkonen, \& Laine, 2012). Thus, it can be assumed that Finnish teachers learn already in teacher education to interact with curriculum materials in the relevant manner. Furthermore, according to Pehkonen (2004), teachers consider Finnish curriculum materials simultaneously to guarantee a consistent quality of teaching and support reforms in mathematics education. Still, very little is known about Finnish mathematics education, although there have been several attempts to reflect on Finnish success in this area (see e.g., Ryve, Hemmi \& Börjesson, 2011; Andrews, Ryve, Hemmi, \& Sayers, 2014; Niemi, Toom, \& Kallioniemi, 2012; Pehkonen et al., 2007; Hemmi \& Ryve, 2015b). The same concerns knowledge of the qualities of Finnish curriculum materials, despite their popularity. Only a few studies of Finnish mathematics textbooks have been published (e.g., Törnroos, 2005; Wikman \& Horsley, 2012). Currently, there is a growing interest in applying Finnish curriculum materials in other countries, which may be problematic given that we have limited knowledge about the materials and the rationales behind them (Hemmi \& Krzywacki, 2014). Hence, our investigations of curriculum materials are likely to increase our understanding of the Finnish mathematics classroom culture.

In the present study, the term 'curriculum materials' refers to commercially produced materials used in school education, such as student textbooks and teacher guides (TGs). The study focuses on teacher guides for Grades 1-6 and aims to address the following question: What kinds of resources do Finnish mathematics teacher guides (Grades 1-6) constitute for teachers?

We commence by elaborating relevant research and in the following section give an account of the methodological issues. The results are then presented in two sections where the first focuses on the contents of the TGs and the second on the nature of communication referring to how the TGs communicate to teachers. We conclude with a discussion of the results in the light of earlier research and theories.

\section{Curriculum Materials as a Resource}

There are several ways to characterise curriculum materials as a resource for teaching and learning mathematics. Brown (2009) investigated the relationship between a teacher and curriculum materials from a socio-cultural perspective and stated that tools such as curriculum materials can both enable and restrict various kinds of teacher and student actions in practice. The way mathematics is taught results from the interplay between the characteristics of the curriculum materials and the teacher, with his/her specific skills, goals and experiences, as well as views of what constitutes good teaching (see also Brown \& Edelson, 2003). The character of curriculum materials also influences the interplay. Recently researchers (e.g., Davis \& Krajcik, 2005; Schneider \& Krajcik, 2002) have started to emphasise the educative nature of curriculum materials (i.e., that materials have the potential to enhance teacher learning if they encompass an elaborated attention to the process of implementing the curriculum). Davis and Krajcik (2005) have even established a set of guidelines that could be utilised when producing TGs which are specifically to support teacher learning. These ideas originated from Ball and Cohen's (1996) well-established ideas 
about Mathematics Knowledge for Teachers (MKT) and the special support teachers might need in their work in terms of knowledge domains.

Further, some researchers have approached curriculum materials by characterizing the way they are organised and how they communicate to teachers (Brown, 2009; Remillard \& Reinke, 2012). According to Remillard (2000), there has been criticism against curriculum materials characterised as "speaking through a teacher"( i.e., materials that dictate teachers' precise actions in the classroom). It might not be appropriate or suitable to provide only one particular way to proceed in the classroom if, for example, flexible assessment procedures are to be carried out or the various needs of individual students should be addressed. Instead, Remillard (2000) introduced the idea that the materials could 'speak to a teacher' as a solution for flexible customisation. Brown (2009) addressed the same issue by using the concepts procedure-centric and resource-centric, which are in line with the previous approach. Procedure-centric materials focus on carrying out the lessons and performance in the classroom; whereas resource-centric materials communicate the main ideas and curricular features but leave the details of implementation for teachers to design.

Accordingly, Remillard and Reinke (2012) investigated curriculum scripts guiding teachers in planning and enacting mathematics lessons using two categories: explicit script and descriptive script. An explicit script paves the way for a teacher by describing how to speak and act in the classroom and, hence, is close to Brown's procedure-centric approach. For example, the TG might contain specific sentences that teachers should use with students, illustrations of what to draw on the board, or tips for how to carry out a certain activity. A descriptive script, which is close to Brown's concept of 'resource-centric,' supports teachers by informing them about underlying ideas at a general level but includes no detailed instructions for teaching mathematics in the classroom, for instance, what to say or how to act during certain activities. Thus, teachers need to develop their own methods of implementing the ideas in the classroom. The potential of curriculum materials to be used in flexible ways is influenced by several factors. Remillard and Reinke (2012) attempted to capture the flexibility of the use of flexible materials by identifying ways of approaching customisation. Similarly, Brown (2009) suggested that there is a balance between being sufficiently open-ended to accommodate flexible use and, at the same time, being sufficiently constrained to provide coherence and meaning with respect to the intended uses of various users.

Remillard and Reinke (2012) also discussed the educative potential of explicit and descriptive scripts. They concluded that while explicit scripts offer more concrete instruction for acting and communicating in new ways, descriptive scripts may broaden teachers' repertoire by offering information about students' possible solutions and examples of ways to proceed. Brown (2009) as well as Remillard and Reinke (2012) stated that discussing the rationales underlying the choices of and suggestions for activities is the key to improving the educative nature of curriculum materials (cf. Davis and Krajcik, 2005). We claim that the educative nature of materials can be connected to different kinds of learning. The materials may enhance general teacher knowledge-knowledge that a teacher can, depending on his/her design capacity (see Brown, 2009), apply in different situations. The educative nature of materials may also be close to specific classroom situations and practices, and they enhance ability to act in new manners by utilizing various artefacts in the classroom (e.g. Wenger, 1998; Remillard, 2005). 


\section{Methods}

\section{Data}

We analysed Finnish curriculum materials that, altogether, covered about 90 percent of the curriculum materials used in Finnish schools (Joutsenlahti \& Vainionpää, 2010). Laskutaito (Numeracy ${ }^{1}, \mathrm{Nu}$ ) and Tuhattaituri (Jack-of-all-Trades, JT) covered about 83 percent of all materials on the Finnish market in 2008 (Joutsenlahti \& Vainionpää, 2010). Numeracy has dominated the market since the 1990s; while Jack-of-all-Trades has become more popular during the past decade, covering approximately 25 percent of the whole market in 2008. We also chose two newly produced materials, Matikkamatka (Math Journey, MJ) and Matikka (Math), in order to analyse recent trends in Finnish curriculum materials.

Sample lessons for the analysis were selected by choosing topics that represent different mathematical areas and central themes at different grade levels. The idea was to select such topics from various grade levels that would allow us to comparing like materials and also characterise the materials as a resource in general. We analysed a sample lesson as well as the general introduction to the material and the introduction to the unit supporting the chosen lesson from each of the four TGs for Grades 1, 3, and 5-6. The aim of the analysis was not merely to describe the organisation of the material as such but to analyse the intended support for giving a particular lesson in terms of provided content and the nature of communication. This allowed us to investigate the TGs across the elementary school years and to reveal possible patterns in the materials.

The chosen topics were:

- Numbers 0 and 1 (Grade 1)

- Subtraction algorithm with crossing number units (Grade 3)

- Introduction of percentages (Grade 5 or 6 depending on the material)

\section{Method of Analysis}

The authors of this article conducted all the analyses of the TGs described in this section. All the three researchers who participated in the data analysis master Finnish as a mother tongue, and thus, it was possible to carry out the analysis of the material in original language, Finnish. We commenced our analysis of the TGs by seeking to obtain an overview of the organisation and characteristics of the material using iterative cycles of analysis as recommended by previous research (Bryman, 2012). This was needed to deepen our understanding of the general features of the TGs and to develop an analysis tool that would specifically address the special features of Finnish TGs in terms of content and the nature of communication. In this phase, the data were divided into units of analysis representing units of meaning that would be possible to categorise using an analytical tool.

We then categorised the data in terms of content areas and took the framework originally developed by Davis and Krajcik (2005) as our basis. In practice, our initial categorisation was based on an already modified framework developed by Hemmi, Koljonen,

\footnotetext{
${ }^{1}$ The titles of the TGs have been translated from Finnish to English by the present authors.
} 
Hoelgaard, Ahl and Ryve (2013), which consisted of the following five categories: 1) General knowledge of and encountering students' thinking; 2 ) Concepts and facts within mathematics; 3) Mathematical progression and connections; 4) Rationale behind the activities; and 5) Design of teaching. During the initial stages of the analysis, we determined that the categories were overlapping and interconnected. Additionally, they did not cover the entire content profile of the Finnish material. For example, the fourth category 'Rationale' is not in line with other content categories aimed at particular topic areas but rather describes the mode of communication, and the fifth category 'Design of teaching' overlapped with at least the first category. The challenge was also to modify the analytical tool in such a way that the original terms and contextual issues of Finnish school mathematics were taken into account. Several cycles through the data were required to construct and consolidate an analytical tool we could use to analyse the data in a consistent and trustworthy manner. We conducted parallel analyses in order to ensure that we interpreted the data in relation to our categories in a similar manner. The only conflicts were about the category of rational that concerned only a few analysis unit and these conflicts were solved out in cooperation in research group. This enhanced the reliability and the validity of the data analysis. Due to the similar structure with the same reoccurring activities, the findings can, concerning these activities and the general patterns, be generalised to the entire series. Concerning rationales behind the activities and other general information, Jack of All Trades differs from the three others because this kind of information was also offered in connection to the lesson pages. This had to be also taken into account when interpreting the results and when comparing the series with each other. Three main content categories were established: a) The use of curriculum material, referring to descriptions of and instructions for use; b) Concepts and facts within mathematics (cf. Davis \& Krajick, 2005); and c) Pedagogical support for teaching and learning mathematics. Pedagogical support included the following: 1) Mathematical connections and progression, including lesson objectives; 2) Classroom instruction; 3) Mathematical communication; 4) Assessment and attending to different learners (differentiation); and 5) Parental cooperation and homework compliance (see Table 1). As is common during such an analytical process, a unit of analysis could cover more than one content category. Thus, the categorisation was not exclusive, and an analysis unit could be included in more than one content category if needed.

We conducted further analysis by investigating the character of the TGs in terms of the way in which the material communicates with teachers. First, in the initial analysis, we had noticed that three different text levels should be considered when conducting and interpreting a more fine-grained analysis of the material due to the different functions that the levels serve in the material. The first level discusses issues of teaching and learning mathematics on a general level that the text is not intertwined with any unit or lesson in particular. In practice, these parts could be moved somewhere else without breaking the overall structure of the material. The second is the unit level, referring to a particular grade level or teaching units in the material. The third is the lesson level, which is most closely related to the classroom practice by referring to planning and organizing a particular lesson. 
Table 1. Content categories for analysing Finnish TGs

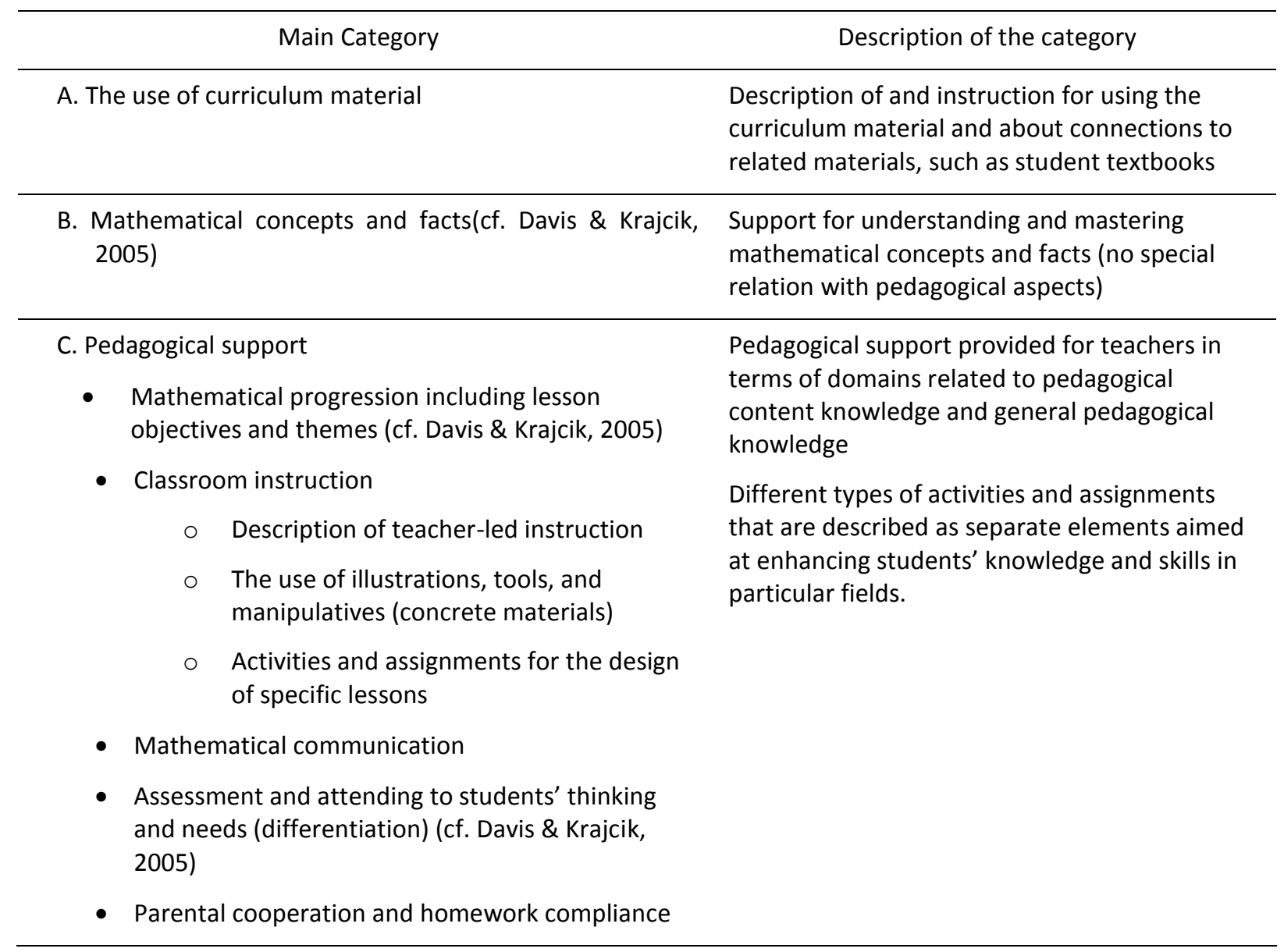

It is noteworthy that the different levels of the text do not always follow the expected structure of the material, for instance, text excerpts at the general level can be found in the lesson pages, and ideas for classroom practice are discussed occasionally in the introductory part. Jack-of-all-Trades differs from the others by offering general pedagogical support more in connection with lesson descriptions rather than on a general/unit level. Because of our methodological choice, we have only analysed the sample lessons and, therefore, cannot make statements about the extent of general pedagogical support in these series.

Second, the nature of communication was characterised by analysing the mode of the text using an analytical approach developed by Remillard and Reinke (2012). Hence, we made the distinction between descriptive and explicit utterances. If it were impossible to characterise only within one category, we used a category of blended mode instead that refers to a mix of both descriptive and explicit characters used in a single item. Moreover, a special feature of Finnish TGs is that they partly communicate through lists, figures, and tables, which were considered to form a fourth category used for identifying the mode of the text. Thus, we needed to further develop the original analytical tool that is originally for scripts that describe ideas using full sentences and clear threads of a procedure.

The third way to characterise the nature of communication was to analyse whether or not a rationale behind the suggested activities was given (cf. Davis \& Krajcik, 2005). This aspect was adapted from the original framework for characterizing educative curriculum materials. Each analysis unit was scored dichotomously for a rationale being present of not. 
Fourth, the way material communicates was analysed in terms of the flexibility of use, which refers to different types of customisation. In practice, the material was initially characterised by following the framework of Remillard and Reinke (2012), which has four distinct categories. The first category of flexibility of use refers to a specified content that is to be followed during the lesson and that hardly leaves room for adaptation. The three other categories describe flexibility on different levels: illustrative examples, contingency, and pedagogical options. Illustrative examples shed light on the idea of specific activities and give options for teacher talk and activities in a particular situation. Contingency refers to suggestions that are dependent on students' performance and actions,; thus, it is connected with classroom situations and assessment. The highest level of flexibility consists of pedagogical options, which refer to teachers' possibility to choose from a collection of pedagogical ideas and ways of organising mathematics education. For example, optional assignments and teaching methods are discussed as possibilities to be taken into consideration by teachers.

The content analysis we carry out does not allow us to quantify and compare the books with each other in terms of number of references to a particular theme. Moreover, the emphasis on a particular theme must be interpreted in relation to the chosen data excerpts, which illustrate the support provided for a single lesson. We exemplify the results with data extracts that we have translated into English with help of an expert in both Finnish and English, in order to make the analysis more transparent and to offer the reader authentic examples from the materials.

\section{Contents of the Teacher Guides}

Three main content categories constitute the basis for profiling the TGs: Information about the use of material, Mathematical concepts and facts, and Pedagogical support (see Table 1). The extracts we refer to often exemplify several aspects of results and; therefore, they are sometimes connected to different parts of the text.

\section{The use of curriculum material}

All of the TGs provide rather detailed descriptions of different parts of the materials. These descriptions are mostly located at the beginning of the guide, in the introductory part and partly at the beginning of the units. They clarify the purpose of several parts and additional sections of the material and other provided material. The authors of the TGs also offer information about the structure and content of students' textbooks with the enclosed concrete material, CDs with songs, extra tests, and web-based interactive material. When presenting students' textbooks, all TGs point out the place of homework in student's lesson pages as well as pages for individualising teaching in connection with every lesson. The additional assignments, for example, copy sheets, are classified and listed in a table in all but Jack-of-all-Trades, and they also in some way indicate the purpose and/or the level of the separate sheets.

\section{Mathematical concepts and facts}

Mathematical concepts and facts are hardly discussed in any part of the materials. Math Journey provides discussions on some basic concepts, such as percentage. Moreover, each grade level of Math Journey includes a few separate pages for mathematical terminology 
with short descriptions. Most of these concepts are relevant also for students, so they do not aim at enhancing teachers' mathematical knowledge beyond the level required of students. Only occasionally are mathematical concepts discussed on the lesson-level pages in Jack-of-all Trades, which sporadically offers short informational texts about mathematical concepts or historical facts connected to the lesson theme, while the other two series do not provide mathematical background or support for mathematical facts as such.

\section{Pedagogical support}

Pedagogical support is an essential theme in all TGs, and it is comprised of several themes discussed in the materials: 1) Mathematical progression and objectives; 2) Classroom instruction; 3) Assessment of and attending to different learners (differentiation); 4) Mathematical communication; and 5) Parental cooperation and homework compliance (see table 1).

\section{1) Mathematical progression and objectives}

All TGs declare in rather great detail the objectives and central content as part of the lesson pages as well as in the introductory pages of the particular unit. For example, learning contents and goals for a unit dealing with percentage (Extract 1) are presented focusing both on students' understanding of the concept of percent and of the relation between decimal fraction, fraction and percentage, as well as students' capability of using this relation in argumentation and applied problems. Further, mental arithmetic, written procedures reasoning, and problem solving are all addressed in the contents and goals. Finally, it states that play activities and exercises are to support students' mental calculation and reasoning skills (Extract 1 )

Extract 1 (Nu 6, p. 10) Contents and goals for learning

- A student understands the concept of percent.

- A student learns about the relation between decimal fraction, fraction and percentage, and can apply this in argumentation and problem solving.

- A student can calculate mentally $1 \%, 10 \%, 20 \%, 25 \%$, and $50 \%$ of given numbers.

- A student learns to calculate any percentages from an arbitrary number using a percentage factor and paper and pen and/or calculator.

- A student learns to calculate how many percent a number is of another number.

- A student learns to calculate the value of the changed number, when the change is given as percentage.

- Students use and improve their mental arithmetic and reasoning skills as well as creativity through different play activities and exercises.

However, the way mathematical progression and general goals of learning mathematics are approached varies between the materials. Jack-of-all-Trades constitutes the greatest exception by hardly discussing the objectives of instruction yet listing the main topics to be learned at a lesson level and offering some general thoughts on grade-level objectives in connection with lesson pages. The three other series, in contrast, all state objectives for every lesson and discuss more general objectives and the mathematical progression also at a more general level. Particularly Math and Numeracy aim to give a clear overview of the mathematical progression both at the grade level as well as related to each lesson. 


\section{2) Classroom instruction}

Classroom instruction at lesson level is a theme that all the TGs approach quite profoundly. All the TGs describe some general ideas concerning teacher-led instruction of various mathematical topics at some level. For example, both Math and Math Journey give special attention to learning numbers in the first grade at the grade level. At the lesson level, there are ideas about teacher-led instruction about the specific topics of a lesson offered in all the guides (see subtraction algorithm in Extract 2 and 3).

Extract 2 (JT 3, p. 42)

\section{Suggestion for proceeding the lesson}

1. A frame story

2. Exploring the picture

It is possible to illustrate with aid of Slide 10a how to regroup (borrow) in subtraction algorithm (301-154) step by step. Detach the hundred square from the top of the slide. When borrowing from the hundreds, this hundred square should be moved above the tens. Next, one ten will be detached from the hundreds and moved above ones. Only then is it possible to do the subtract algorithm. The subtraction is carried out synchronously on the slide.

3. Working on the board

Three pupils calculate tasks on the board. Then they explain their calculations to the others.

4. Mental calculation

5. Textbook tasks

Extract 3 (MJ 3, p. 34)

\section{Teaching}

Subtraction with regrouping over zero is a demanding procedure that appears now for the first time. Let's visualise a couple of tasks by using ten base blocks and ten base board or corresponding overhead slides (attachment 77).

- Illustrate the original number/minuend (4003) concretely by using ten blocks.

- Subtract concretely as many as the second term indicates (1545).

[A picture of the subtraction algorithm is described above]

- Let's calculate how much is left, working column by column from right to left starting from ones. Borrowing from thousands and regrouping hundreds and tens into ones.

- The procedure is written down synchronously on the board or overhead slide step by step.

Algorithm tasks are calculated together without any support of concrete materials.

It is worth checking the subtraction algorithm by adding from the bottom upwards. $\cdots$

Utilizing manipulatives and illustrations can be seen as part of the support for instruction of a specific topic, and it is discussed and seen as somewhat important for quality instruction in all four TGs. Specific models and/or ideas for concretising teaching related to particular lesson themes are found to a varying extent in every guide (see the use of base ten tools for illustration of subtraction algorithm in Extract 2 and 3). It is also connected to remedial education in forms of offering "preventive support" to struggling students by activities where students think aloud and use concrete material (Extract 4), supporting student 
thinking in mental arithmetic tasks (Extract 5), and carrying out ten transitions (Extract 6). Illustrations are regularly used in Jack-of-all-Trades as a base for whole class discussions (Extract 2 and 7).

Extract 4 (Math 3, p. 36)

Big numbers, saying out them aloud, writing them as well as arranging them in order are difficult for a student who needs special support.

Several regrouping phases and borrowing over zero in the subtraction algorithm may cause difficulties. It is important to provide preventive support and practice a lot by using concrete material and the thinking-aloud method.

Extract 5 ( $\mathrm{Nu} 1$, p. 10)

Some pupils need fingers or blocks to help with mental arithmetic tasks. It is beneficial to allow this and even encourage them to use tools, as it is often impossible for them to solve the tasks without them. Using blocks and fingers is slow and laborious, so the pupils will give up using them when they are able to solve the problems in their minds. Use of tools is an intermediate step in training for this.

Especially during the first term of the first grade, pupils can at times answer with their number cards. Then the teacher can see when all the pupils are ready.

Extract 6 (Nu 3, p. 114)

\section{Remedial education}

It is good to provide remedial education by using concrete materials if there are pupils in the classroom who cannot carry out cross ten transition of one-digit numbers. Abacus beads, for example, consisting of two-colour beads are suitable material $(10+10)$. It is also possible to utilise ten egg cartons and foam balls. The aim is to achieve a level of automation. This is important for the fluency of algorithms.

Extract 7 (JT 1, p. 14)

Exploring the picture

1. What are the names of the children in the picture? (Antti and lida)

2. What does lida have singly but Antti has none? (for example, a key, a pony tail, or a hair band)

3. What does Antti have singly but lida has none? (for example, a book or a cap)

4. How many children do you find in the picture? (2) How many adults do you find in the picture? (1) How many fewer adults are there than children? (1)

5. The clock under the picture shows exactly one o'clock. Where is the red short hand pointing to? (number 1) Where is the long blue hand pointing to? (straight up to the number 12)

Additional activities and assignments at the lesson level comprise a special category for describing the support for classroom teaching offered by Finnish TGs. They are separate elements, which can be found regularly in each lesson description each teacher can utilise in designing and enacting mathematics lessons. All the TGs follow a repeated structure concerning task and activity types. For example, mental calculation (Extract 8) and problem solving (Extract 9 and 10) can be found regularly in the lesson pages of each TG at all Grade levels, and thus, it can be assumed that they are considered an important part of teaching and learning mathematics. 
Extract 8 (JT 1, p. 14)

Mental calculation

1. There is a man walking the dog in the picture. He has three more dogs at home. How many dogs does the man have in all? (4)

2. Antti has a book in his hand and a book in his bag. lida also has a book in her bag.

How many books do the children have all together? (3)

3. Antti has 5 coloured pens in his bag. lida has one less coloured pen than Antti. How many coloured pens does lida have in her bag? (4)

Extract 9 (Math 1, p. 27)

\section{Brain-teaser}

1. There are two hens standing behind the fence. How many feet can you see under the fence? (4)

2. There are two cows standing behind the fence. How many feet can you see under the fence? (8)

Extract 10 (JT 6, p. 68)

'Problem corner'

Give your answer in fraction format.

1. What is $10 \%$ of a percent? (1/1000)

2. What is a half of a percent? $(1 / 200)$

Mental calculations are connected either to the current topic, or they might provide repetition of previous topics while brain-teasers of each lesson are related to various topics. Besides mental calculation and problem solving, all TGs offer ideas for cooperative activities, such as games and playing activities for every lesson (Extract 11).

Extract 11 (Nu 1, p. 17)

A counting play

Pupils sit in a circle. There might be two circles instead in a bigger class. Numbers

1-10 are counted going around the circle. After reaching ten counting starts again

from the beginning, number 1 . The pupil who says 10 sits down. The play

continues until only one pupil is standing. The play is to be repeated by counting

the numbers backwards from 10 to 1 . Then the pupil who says number 1 sits

down.

\section{3) Mathematical communication}

Mathematical communication is in focus in most activities suggested at the lesson level in the TGs. Besides, it is also addressed occasionally explicitly at the general level, for example, by suggesting that problems could be solved through discussion in the whole class or by stressing the importance of combining speech with the use of concrete materials (Extract 4), introducing new concepts and their connections to other concepts (Extract 12), and assessing student learning (Extract 13).

Extract 12 (Math 1, p. 13)

\section{Communication and explaining}

Introduce new concepts carefully by telling about their relation to other concepts. Repeat the concepts often enough in oral communication. Organise short sessions for mathematical communication. The whole class will benefit from them. Let the students explain as well.

Extract 13 (Math 1, p. 13) 


\section{Thinking aloud}

If a pupil is clearly having problems learning a topic or concept, provide him/her remedial teaching or a small group supervision and encourage him/her to tell about his/her own thinking. Thus wrong kinds of thinking models will be revealed, and it is possible to correct such thinking.

Narratives and pictures to be used as basis for mathematical communication connecting the topic of the lesson to everyday contexts can be found as a separate activity for every lesson in Jack-of-all-Trades and Math (Extract 14 and 2).

Extract 14 (Math 5, p. 142)

A story

Aino and her mother are browsing shops during the last spring sales. The very last winter equipment is to be sold in order to make room for light and colourful summer clothes.

"Now it is time to prepare ourselves for next winter when there are such substantial price reductions," says the mother while fiddling with a heavy quilted jacket. "Look, 50 percent off the price of almost every jacket!"

"Why have the reduced prices not been marked in Euros?" Aino wonders. "Then it would be much easier to know the actual price of a jacket."

"This is an easy way for the store to handle it, reflects the mother. It's much easier to just announce that all the jackets can be bought at half price than to calculate a separate price for each jacket."

"Half the price?" Aino wonders.

"Yes...50 percent equates to 50 hundredths that is the same as a half," her mother explains.

"But then you get a better discount in euros on an expensive jacket than on a cheaper one," Aino notices. "How much more is the discount on a 100 Euro jacket than on a 70 Euro jacket in euros if the sale is for 50\%?" (15 Euro)

\section{4) Assessment of and attending to different learners}

The profiles of the TGs vary regarding the pedagogical support they offer. The greatest difference can be seen in how the TGs address assessment and testing, approaching various learners, and attending to students' thinking. All the TGs offer formative and summative tests, but only Math and Math Journey discuss assessment in some detail at the general level, also addressing students' self-evaluation and formative judgment (Extract 15 and 4). As shown in Extract 15, it is stressed that the most important task for the teacher is to be aware students' potential regarding mathematical skills and knowledge.

Extract 15 (MJ 3, p. 294)

Some other assessment methods are needed in addition to written tests in order to evaluate pupils' skills in various ways. The role of an active learner also concerns self-assessment. Therefore, there are evaluation sheets available after the test answers. Self-assessment improves a realistic attitude to one's own skills and helps students to set learning goals.

The assessment of the learning process presumes systematic follow-up of learning. The object of teaching is to develop students' mathematical skills. Thereby it is essential to canvass what a student has already mastered. Typically, continuous individual observation and assessment are required. Often this results in a need to reconsider and revise the original teaching plan. 
Numeracy pays less attention to assessment procedures other than highlighting the needs of various learners at the general level. They raise, for example, motivational aspects such as fear of mathematics and offering 'preventive support' for struggling students and challenges for gifted students. Moreover, both Numeracy and Math sometimes inform teachers about what may be difficult in the next area and how to prevent students having difficulties (Extract 4).

Jack-of-all-Trades is a striking exception concerning assessment compared to the other series. It neither attends to student thinking nor to assessment procedures despite a few remarks on a possible diagnostic test at the beginning of grade 1 and some references to material for struggling students or students who can already read at the lesson level. Actually, assessment is hardly discussed in relation to individual lessons in any of the TGs, although all of the TGs regularly offer extra material for struggling students and for students who need challenges.

\section{5) Homework and cooperation with parents}

In all of the TGs, homework is only mentioned and sometimes shortly described in the introductory pages when pointing out the location of homework assignments in student textbook, and cooperation with parents outside the classroom is a marginal theme that is mentioned only in Math.

\section{Nature of Communication}

The results presented above enlighten the content of the support that TGs provide for teachers. The nature of communication is equally important when profiling the characteristics of TGs as a teaching and learning resource. We commence with a short summary of the levels of support and their connections in the TGs. Then we approach the nature of communication by looking at three aspects: 1 ) mode of the text; 2 ) rationale behind the suggested activities and procedures; and 3) flexibility of use.

The nature of support depends on what level it is offered. Support at the general level and Grade level can be considered as enhancing teachers' general knowledge for teaching that could be applied in different contexts and situations. Explicit descriptions of how to combine support at the general level and unit level with lesson-specific ideas are seldom offered by the guides. There are only few differences between the book series concerning this matter. The amount and emphasis of general text parts is quite similar and located in the introductory pages in all but Jack-of-all-Trades, which seems to provide little support at the general level but the most support on the lesson pages. We have analysed the mode of the text at all levels and even at the level of the separate lesson assignments included in the sample.

\section{Mode of the text}

In general, all the TGs tend to provide rather general information for teachers instead of explicit scripts for proceeding with a particular lesson. All of the TGs are primarily descriptive at least at the general and unit levels, (i.e., they communicate to the teacher) (cf. Remillard, 2000). A teacher is offered information on various themes on the whole, but he/she has to decide autonomously how to act and carry out activities precisely in the classroom. It is common to use lists, tables, and figures when communicating about ideas at all levels.

None of the TGs offers a detailed description of exactly how to proceed during a whole lesson at any level, but rather they describe a number of separate activities and examples 
that teachers could utilise in planning and in enacting classroom instruction. Jack-of-allTrades includes a suggestion for how a lesson could proceed (Extract 2), but it can also be regarded mostly as lists of separate activities connected to the lesson topic. It offers several assignments and activities for each lesson other than those mentioned in the suggestion.

Most of the teacher-led instructions at the lesson level are blended in mode, although they may sometimes be quite detailed like in Math Journey. It has a step-by-step instruction about how to proceed with base ten materials when introducing subtraction with regrouping/borrowing for the first time at Grade 3 (Extract 3).

The tasks for mental calculations (Extract 8 ) and problem solving (Extract 9 and 10) are given explicitly in the form of ready-made questions and answers that a teacher can use in the classroom as such. However, some suggestions about how to deal with these tasks are offered only in Numeracy where ideas of connecting concrete material and number cards to mental arithmetic (Extract 5) and ideas of how the teacher could proceed with problem solving tasks (Extract 16) are offered.

Extract 16 (Nu 3, p. 5)

\section{Problem solving}

...It is possible to practice problem solving either individually or as group work. An option is, for example, to introduce a problem in the morning and then leave it to the students to solve it. Then, the class can explore together how to solve the problem and find the right answer before the school day ends.

In contrast, the other optional activities and assignments, such as how to proceed with games and play activities, are quite explicitly described as is shown in Extract 11 presenting a sequence play. Further, Jack-of-all-Trades offers rather detailed ideas about the questions teachers should pose (as well as expected student answers) in order to focus on relevant mathematical aspects with the help of a picture offered for every lesson (Extract 7).Finally, Jack-of-all-Trades also offers an explicit description of what to write on the board for every lesson. Hence, there are quite explicit parts in the TGs that could be considered as talking through a teacher (cf. Remillard \& Reinke, 2012).

\section{Rationale}

The rationale behind the ideas is reflected on occasionally in the TGs. Concerning the content with information about the use and structure of the material, none of the TGs provides a thorough description that would help the user understand the ideas underlying the different parts and the connections between them. Only some motivations related to the suggested reoccurring activities or pedagogical themes, such as individualisation and addressing the needs of learners, are given for justifying the need to use these themes. Numeracy states that the reoccurring activities like problem solving and games are for providing ideas for creating meaningful learning situations in mathematics classroom (Extract 17).

Extract 17 (Nu 1, p. 11)

There are ideas of mental calculations, brain-teasers, exercises, and play activities or suggestions, from which a teacher can choose from the ones s/he likes and modify them if needed. The aim is to facilitate teachers' planning work and offer ideas for making learning of mathematics more engaging, more versatile, and deeper. 
All TGs, except Jack-of-all-Trades, which only lists the concrete material accompanying student textbooks, provide a list with descriptions of relevant use of concrete materials useful for teaching and learning of specific content at a particular grade level. However, the information about the use of the material is mostly approached by naming the different parts, describing them, and indicating their location in the material.

Concerning the rationale behind the pedagogical support, all the TGs include some motivation for the main topics of teaching and learning mathematics, such as proceeding from the concrete through mental strategies to automation (Extract 6) and about the conceptualisation processes in mathematics (Extract 18). Also, the rationality behind the use of talk and concrete materials is sometimes discussed in more detail (Extract 18).

Extract 18 (MJ 1, p. 10)

Speech plays a central role in the mathematical conceptualisation processes. The use of familiar terms in relation with concretising activities helps children to associate new mathematical concepts with prior concept schemes.

Math Journey offers a motivation for different kinds of student evaluations by highlighting, for example, the meaning of self-assessment for active learning process and improving self-knowledge as mathematics learner (Extract 15).

Numeracy differs from the other TGs in that the rationales behind the given ideas are discussed rather widely. This is partly due to the style of communication, as Numeracy is written in a more thoughtful manner, using whole sentences. The other three TGs include much less discussion of the rationales behind the ideas. Descriptions are generally short, and for mental arithmetic and problem solving, only the tasks including questions and correct answers are presented. For example, in connection to the instructions for activities with struggling students, concrete materials are raised as helpful for achieving fluent algorithm skills (Extract 6). Only Numeracy offers a rationale for mental arithmetic and problem solving. Concerning the suggested mental arithmetic tasks Numeracy states that they help a child develop understanding of mathematics as part of everyday life and mastering operations (Extract 19). The importance of problem solving activities is motivated by students' need to search for regularities, order, classify and practice logical reasoning (Extract 20).

Extract 19 (Nu 1, p. 6)

\section{Mental calculation}

Mental calculation plays an important role in learning mathematics. While solving such problems, a child strengthens their relation between mathematics and the everyday world. It is impossible to apply mathematical knowledge and skills without such connections.

Another important aim is to improve the fluency and accuracy of numeracy by mental calculations. Mechanic mental calculations also serve this purpose.

Extract 20 (Nu 3, p. 5)

Problem solving

[Problem solving] tasks provide exercises for finding patterns and differences, ordering, classifying, and practicing logical reasoning.

No further overall rationale for the co-operative activities, such as games and playing activities, is provided at the lesson level. For example, why and how to select and combine separate tasks, in the best way, for use in a classroom is absent. This also applies to pedagogical support for classroom instruction and utilizing different elements to design a 
lesson or teaching sequence. No thorough discussion on rationale is provided to enhance the pedagogical understanding or to pave the way for forming a meaningful and coherent lesson, including particular types of activities. Only the extra tasks and work sheets offered for every lesson in each guide are often referred to as support for struggling students, extra training or challenges.

\section{Flexibility of use}

Flexibility can be considered at different levels: planning for a unit, design of a lesson, or within the suggested separate lesson elements/activities. There are some minor differences between the TGs in terms of flexibility of use( i.e., in what way the content of the TG is presented concerning the limits of incorporating ideas into one's own work). Overall, the Finnish TGs seem to be relatively normative. They often state that "it is good to proceed" in a certain way, "pupils need," "a teacher needs," etc., but all of the guides also regularly use "the teacher can," "we recommend," or "it is beneficial" at the different levels of communication. Both Math and Numeracy particularly stress the importance of the teacher choosing and applying the proper ideas in their design of teaching. Numeracy stresses the importance of autonomy that teachers have when choosing teaching methods but still provides various ideas for diversifying activities in the classroom (Extract 21).

Extract 21 (Nu 1, p. 4)

Numeracy 1 does not obligate or constrict a teacher in choosing the teaching methods. It is worthwhile to bravely try various working methods. The TG offers ideas for activating exercises, games, and play activities, for instance, that suit working in pairs or in groups.

Numeracy also informs that the reoccurring activities like mental arithmetic, problem solving and games are only suggestions that a teacher can utilise in flexible ways for own purposes (Extract 17).

Illustrative examples are used, for example, at a general level in a form of a table in Math Journey that shows different situations for applying addition, subtraction, multiplication, and division (MJ 1, p.11). Math Journey 1 also offers many examples at unit level concerning how to proceed when introducing new numbers. Math calls its ideas for teacher-led instruction at the lesson level for "Teaching examples" and also offers examples within its description of teaching, as does Numeracy. The way in which teacher-led instruction is described is often quite open-ended in all of the guides and leaves the teacher to modify and proceed in different manners. Still, Jack-of-all-Trades and Math Journey offer examples and alternatives more seldom than the other two series do at the lesson level. Contingency scripts are explicitly represented in Numeracy and Math, which at the general and unit level connect the given ideas with a possible classroom situation and the progress of learners. These two book series also further discuss various learners and ways to attend to students' thinking, which makes the idea reasonable (Extract 6 and 7).

All the guides offer separate activities for different learners at some level of information, and all of the guides offer differentiating tasks at the lesson level that can be connected to the aspect of contingency in the case of customisation (Remillard \& Reinke, 2012). Further, all of the TGs offer a great number of different ideas for designing specific lessons. The teacher must then choose among these ideas the ones that suit the class, a specific group, or individual student, as it is impossible to include all of them in one lesson. Hence, there are many pedagogical options and also some contingency concerning the level at which to 
design a lesson using various elements. Yet, Numeracy is the only guide that describes relatively broadly pedagogical options and explicitly states that it is up to the teacher to decide how to implement activities and which elements should be given particular attention in planning and implementing.

\section{Discussion and Conclusion}

Pedagogical support dominates the contents of the guides. Goals, instruction, assessment, and differentiation in teaching methods for various learners are central themes in all of the guides, although they are elaborated differently. The use of concrete materials as part of teaching and learning mathematics is essential in all of the TGs in line with the guidelines in the Finnish national core curriculum (FNBE, 2004). Still, the use of concrete materials is not a theme that is systematically elaborated at all levels of communication. Hence, proper use of the materials presupposes a teacher has knowledge about the rationales underlying them. Assessment is given rather little attention considering that it is mainly the Finnish teachers themselves who design and carry out assessment procedures in the classroom (Krzywacki, Lavonen \& Juuti, 2014). Furthermore, homework, which constitutes an essential element in Finnish school education (Krzywacki et al., 2012; Hemmi \& Ryve, 2015b), is hardly mentioned or discussed from a pedagogical stand point in any of the TGs. It seems that assigning a limited amount of homework after every mathematics lesson is a self-evident part of the Finnish teaching culture, as all of the guides simply point out where the homework is located in the lesson pages of the student textbooks.

The TGs mainly talk to the teacher using descriptive elements (cf. Remillard \& Reinke, 2012). None of the TGs communicates through actual scripts in a chronological order in the form of a lesson manuscript. Instead, common to all the Finnish TGs is that they are based on rather short descriptions, even relying only on lists, tables, and figures to convey the ideas underlying the materials. Therefore, we needed, in particular, to open up the way we understand scripts originally related to lesson descriptions. This indicates that comparing curriculum materials that represent different traditions creates special issues that need to be addressed when we designed the analysis tool. Further, different levels of communication have different functions when interpreting the mode of communication. For example, an overall description or rationale can be offered at a general level and should then be interpreted as something that could apply to topics presented at the lesson level. The overall trend among all four TGs is that they provide pedagogical discussion at a rather general level for teachers as background information but alongside a rich variety of elements describing potential activities and assignments that teachers can choose from. These two aspects seem to be quite separate in most of the TGs. Some variation between the book series can be found, but the materials mainly follow the same pattern and style.

The Finnish TGs provide support for teachers concerning separate central themes, such as attending to student thinking and mathematical progression (cf. Davis \& Krajcik, 2005), but the potential to systematically enhance teacher learning is rather low as rationale behind the suggested activities is seldom made explicit. Improving teachers' mathematical content knowledge (cf. Davis \& Krajcik, 2005) does not seem to be important for the authors of the Finnish TGs. We are aware that the results of our study must be related to a complex dynamic relationship, in which both teachers and TGs play an important role and contribute in a nuanced manner to the enacted practice consistent with other research findings (e.g., Collopy, 2003; Drake \& Sherin, 2009; Gueudet \& Trouche, 2013; Brown, 2009; Remillard, 2000; Remillard, 2005; Pepin, Remillard, \& Bryans, 2004). The presence of illustrative generic 
examples (Remillard \& Reinke, 2012) is not usual in the materials, but we would like to raise the question of the possible generic power of the activities that form the part of the pedagogical options in the materials. Several activities, for example games can be applied in other mathematical situations and the question is if they could enhance teachers' pedagogical design capacity (Brown, 2009), something worth investigating in future studies on teachers' interaction with curriculum materials. In that case, although explicit, they could also be educational.

Many of the elements in all of the TGs are in line with the earlier findings concerning the Finnish teaching tradition (cf. Hemmi \& Ryve, 2015a; 2015b; Hemmi \& Krzywacki, 2014), but the guides seldom offer the overall rationales behind the suggested activities. Understanding these rationales would enhance teachers' understanding of the logic and organisation of the materials, using manipulatives, the role of homework, and the purpose of the specific activities and assignments typical in Finnish mathematics classrooms (Hemmi \& Ryve, 2015a). Finnish teachers obviously have a certain teacher education and outlook on their profession (Krzywacki, Pehkonen \& Laine, 2012) that could support their overall understanding of the ideas in the TGs. Recently, one of the series, Jack-of-all-Trades, has been adapted for Swedish curriculum, but there is no additional information offered in the material that could help Swedish teachers understand, for example, the purpose of the reoccurring activities or how to best use them when designing their teaching (Hemmi \& Krzywacki, 2014). Unfortunately, of the four analysed TGs, this particular series seems to include the least background information and rationales, at least at the general and unit levels.

The present data represent Finnish curriculum materials for elementary mathematics education over the past two decades. It would seem likely, then, that the data could reveal trends in development and change that may have taken place. However, we cannot claim to have observed any clear changes in style during the past two decades despite the more profound style in the mode of communication in Numeracy, the oldest material, which has dominated the market since the 1990s. The question is if the reoccurring activities have gradually become a self-evident part a Finnish cultural script (cf. Stiegler \& Hiebert, 1999; Hemmi \& Ryve, 2015a) and, therefore, are not given so much attention in the materials produced at a later date. Naturally, there are minor differences between the book series, for example, in terms of the way different themes are stressed. However, basically the profiles of the series are rather similar and they follow quite similar patterns. We know from experience that the older and more well-established curriculum materials have been further developed in new editions of the original versions. Moreover, all curriculum materials have begun providing additional digital material, for example, digital tools for designing mathematics tests using task collection and presentation of material for the whole class. We have not analysed the digitalised material as part of the study.

It is worth to consider the possible impact of the quality of the TGs on Finnish students' good results on international evaluations. First, all the TGs are quite homogenous concerning their focus on designing specific lessons, and they comprise similar reoccurring activities in line with views on effective mathematics teaching identified in Finnish teacher educators' discourses (Hemmi \& Ryve, 2015b). Secondly, all of the guides display clear goals for every lesson and offer ideas for teacher differentiations, especially in the form of support for struggling students. Finnish teachers use the TGs to a great extent (Pehkonen, Ahtee, \& Lavonen, 2007), and this could enhance the equity of education. This may be a specific 
feature of Finnish students' results both on national and international evaluations. However, a deeper analysis of the pedagogical ideas combined with how Finnish teachers implement the guides in practice is needed if we are to be able to determine the TGs connection to the quality of Finnish mathematics classrooms.

\section{References}

Andrews, P., Ryve, A., Hemmi, K., \& Sayers, J. (2014). PISA, TIMSS and Finnish mathematics teaching: An enigma in search of an explanation. Educational Studies in Mathematics, 87(1), 7-26.

Ball, D.L., \& Cohen, D.K. (1996). Reform by the book: What is-or might be-the role of curriculum materials in teacher learning and instructional reform? Educational Researcher, 25(9), 6-8, 14. doi: 10.3102/0013189X025009006

Brown, M.W. (2009). The teacher - tool relationship. Theorizing the design and use of curriculum materials. In J.T. Remilard, B.A. Herbel- Eisenmann \& G.M. Lloyd. (Eds.), Mathematics teachers at work. Connecting curriculum materials and classroom instruction (pp. 17-35). New York: Routledge.

Brown, M., \& Edelson, D. (2003). Teaching as design: Can we better understand the ways in which teachers use materials so we can better design materials to support their changes in practice? (Design Brief). Evanston, IL: Center for Learning Technologies in Urban Schools.

Bryman, A. (2012). Social research methods. New York: Oxford University Press Inc.

Cobb, P., \& Jackson, K. (2012). Analyzing Educational Policies: A Learning Design Perspective. Journal of the Learning Sciences, 21(4), 487-521. doi: 10.1080/10508406.2011.630849

Collopy, R. (2003). Curriculum materials as a professional development tool: How a mathematics textbook affected two teachers' learning. The Elementary School Journal, 103(3), 287-311. doi: 10.1086/499727

Davis, E.A., \& Krajcik, J.S. (2005). Designing educative curriculum materials to promote teacher learning. Educational Researcher, 34(3), 3-14. doi:

10.3102/0013189X034003003

Drake, C., \& Sherin, M.G. (2009). Developing curriculum vision and trust: Changes in teachers' curriculum strategies. In J. T. Remillard, B. A. Herbel-Eisenmann \& G. M. Lloyd (Eds.), Mathematics teachers at work. Connecting curriculum materials and classroom instruction (pp. 321-337). New York: Routledge.

Fan, L., Zhu, Y., \& Miao, Z. (2013). Textbook research in mathematics education: development status and directions. ZDM, 45(5), 1-14. doi: 10.1007/s11858-013-0539$\mathrm{x}$

Hemmi, K., \& Krzywacki, H. (2014). Crossing the boundaries: Swedish teachers' interplay with Finnish curriculum materials. Paper presented at the International Conference on Mathematics Textbook Research and Development, ICMT-2014, 29-31 July 2014, University of Southampton, UK. 
Hemmi, K., \& Ryve, A. (2015a). The culture of the mathematics classroom during the first school years in Finland and Sweden. In B. Perry, A. Gervasoni and A. MacDonald (Eds). Mathematics and Transition to School - International Perspectives. Singapore: Springer.

Hemmi, K., \& Ryve, A. (2015b). Effective mathematics teaching in Finnish and Swedish teacher education discourses. Journal of Mathematics Teacher Education, 18(6), 501521. doi: 10.1007/s10857-014-9293-4

Jablonka, E., \& Johansson, M. (2010). Using texts and tasks: Swedish studies on mathematics textbooks. In B. Sriraman, C. Bergsten, S. Goodchild, G. Palsdottir, B. Dahl, B.D. Söndergaard, L. \& Haapasalo. (Eds.), The first sourcebook on Nordic research in mathematics education (pp. 363-372). Charlotte, NC: Information Age Publishing.

Joutsenlahti, J., \& Vainionpää, J. (2010). Oppimateriaali matematiikan opetuksessa ja osaamisessa. [Learning materials in the teaching and learning of mathematics]. In E. K. Niemi \& J. Metsämuuronen (Eds.), Miten matematiikan taidot kehittyvät? Matematiikan oppimistulokset peruskoulun viidennen vuosiluokan jälkeen vuonna 2008. [How do pupils' mathematical skills develop? The learning outcomes in the end of the fifth grade in compulsory school.] Helsinki: Opetushallitus [The Finnish National Board of Education].

Kupari, P. (1999). Laskutaitoharjoittelusta ongelmanratkaisuun. Matematiikan opettajien matematiikkauskomukset opetuksen muovaajina [From practising computational skills to problem solving. Mathematics teachers' mathematical beliefs and the construction of their teaching]. Research reports 7. Jyväskylä: University of Jyväskylä, Institute for educational research.

Krzywacki, H., Lavonen, J. M. J., \& Juuti, K. (2013). There are no effective teachers in Finland-Only effective systems and professional teachers. In Tan, O-S., \& Liu, W-C. (Eds.), Teacher Effectiveness. Singapore: Centage learning.

Krzywacki, H., Pehkonen, L., \& Laine, A. (2012). Promoting mathematical thinking in Finnish mathematics education. In H. Niemi, A. Toom \& A. Kallioniemi (Eds.), Miracle of Education. The principles and practices if teaching and learning in Finnish schools (pp. 115-130). Rotterdam/Taipei: Sense Publishers.

Lloyd, G. M. (2009). School mathematics curriculum materials for teachers' learning: future elementary teachers' interactions with curriculum materials in a mathematics course in the United States. ZDM Mathematics Education 41, 763-775. doi: 10.1007/s11858009-0206-4

Niemi, H. (2012). The societal factors contributing to education and schooling in Finland. In H. Niemi, A. Toom \& A. Kallioniemi. (Eds.), Miracle of education: The principles and practices of teaching and learning in Finnish schools (pp. 19-38). Rotterdam/Boston/Taipei: Sense Publishers.

Niemi, H., Toom, A., \& Kallioniemi, A. (Red.). (2012). Miracle of Education. The principles and practices if teaching and learning in Finnish schools. Rotterdam/Boston/Taipei: Sense Publishers.

OECD. (2013). PISA 2012 results in focus. What 15-year-olds know and what they can do with what they know. Available on: www.oecd.org/pisa. 
Pehkonen, E., Ahtee, M., \& Lavonen, J. (Eds.). (2007). How Finns Learn Mathematics and Science. Rotterdam/Taipei: Sense Publishers.

Pehkonen, L. (2004). The magic circle of the textbook - An option or an obstacle for teacher change. Paper presented at the 28th Conference of the International Group for the Psychology of Mathematics Education.

Pepin, B., Gueudet, G., \& Trouche, L. (2013). Re-sourcing teachers' work and instructions: a collective perspective on resources, their use and transformation. ZDM, 45(7), 929943. Doi: $10.1007 / \mathrm{s} 11858-013-0534-2$

Remillard, J.T. (2000). Can curriculum materials support teachers learning? Two fourth-grade teachers' use of new mathematics text. Elementary School Journal, 100(4), 331-350. doi: $10.1086 / 499645$

Remillard, J.T. (2005). Examining key concepts in research on teachers' use of mathematics curricula. Review of Educational Research, 75(2), 211-246. doi: 10.3102/00346543075002211

Remillard, J.T. (2012). Modes of engagement: Understanding Teachers' transactions with mathematics curriculum resources. In G. Gueudet, B. Pepin, \& L. Trouche (Eds.), From text to 'lived' resources: Mathematics curriculum materials and teacher development (pp. 105-122). Netherlands: Springer. doi:10.1007/978-94-007-1966-8_6

Remillard, J.T., \& Bryans, M.B. (2004). Teachers' orientations toward mathematics curriculum materials: Implications for teacher learning. Journal of Research in Mathematics Education 35(5), 352-388. doi:10.2307/30034820

Remillard, J.T, \& Reinke, L. (2012). Complicating scripted curriculum: Can scripts be educative for teachers. Paper presented at AERA's annual meeting, 2012.

Schneider, R.M., \& Krajcik, J. (2002). Supporting science teacher learning: The role of educative curriculum materials. Journal of Science Teacher Education, 13(2), 167-217. doi: 10.1023/A:1016569117024

Stein, M.K., \& Kim, G. (2009). The role of mathematics curriculum materials in large-scale urban reform. In J. T. Remillard, B. A. Herbel-Eisenmann \& G. M. Lloyd (Eds.), Mathematics teachers at work: Connecting curriculum materials and classroom instruction (pp. 37-55). New York: Routledge.

Stein, M.K., Remillard, J.T., \& Smith, M.S. (2007). How curriculum influence student learning. In F. K. Lester Jr. (Eds.), Second handbook of research on mathematics teaching and learning (pp. 319-369). Charlotte, NC: Information Ace.

Stigler, J., \& Hiebert, J. (1999). The teaching gap: Best ideas from the world's teachers for improving education in the classroom. New York: The free press.

Stylianides, G.J. (2007). Investigating the guidance offered to teachers in curriculum materials: The case of proof in mathematics. International Journals of Science and Mathematics Education 6(1), 191-215. doi: 10.1007/s10763-007-9074-y

Törnroos, J. (2005). Mathematics textbooks, opportunity to learn and student achievement. Studies in Educational Evaluation, 31(4), 315-327. doi: 10.1016/j.stueduc.2005.11.005 
FNBE, (2004). National Core Curriculum for Basic Education 2004. Helsinki: Finnish National Board of Education. Available at:

http://www.oph.fi/english/curricula_and_qualifications/basic_education.

Wikman, T., \& Horsley, M. (2012). Down and up: Textbook research in Australia and Finland. IARTEM e-Journal, 5(1), 45-53.

\section{Teacher Guides}

\section{Laskutaito (Numeracy)}

Rikala, S., Sintonen, A-M., \& Uus-Leponiemi, T. (2008). Laskutaito 1, syysosa Opettajan kirja. Helsinki: WSOY. (Original work published 2001).

Salonen, M., Sintonen, A-M., \& Uus-Leponiemi, T. (2004). Laskutaito 3, syysosa Opettajan kirja ( $9^{\text {th }}$ edition). Helsinki: WSOY.

Koivisto, M., Salonen, M., Sintonen, A-M., Uus-Leponiemi, T., \& Ilmavirta, R. (2007).

Laskutaito 6, Opettajan kirja kevätosa. Helsinki: WSOY. (Original work published 2006).

Tuhattaituri (Jack of all traits)

Haapaniemi, S., Mörsky, S., Tikkanen, A., Vehmas, P., \& Voima, J. (2012). Tuhattaituri 1a, opettajan opas. Helsinki: Otava. (Original work published 2006).

Asikainen, K., Nyrhinen, K., Rokka, P., \& Vehmas, P. (2012). Tuhattaituri 3b, opettajan opas. Helsinki: Otava. (Original work published 2008).

Asikainen, K., Nyrhinen, K., Rokka, P., \& Vehmas, P. (2012). Tuhattaituri 6a, opettajan opas. Helsinki: Otava. (Original work published 2011).

Matikkamatka (Math journey)

Lilli, M., Putkonen, H., Sinnemäki, J., \& Mikkonen, V. (2011). Matikkamatka 1, syksy Opettajan opas. Vantaa: Tammi. (Original work published 2008).

Lilli, M., Putkonen, H., Sinnemäki, J., \& Mikkonen, V. (2012). Uusi Matikkamatka 3, kevät Opettajan opas. Helsinki: Sanoma Pro Oy.

Lilli, M., Ranta, P., Putkonen, H., \& Sinnemäki, J. (2011). Matikkamatka 5, kevät Opettajan opas. Vantaa: Tammi.

\section{Matikka (Math)}

Okkonen-Sotka, P., Sintonen, A-M. \& Uus-Leponiemi, T. (2011). Matikka 1 Opettajan kirja, syksy. Helsinki: WSOYpro.

Rinne, S., Salonen, M., Sintonen, A-M. \& Uus-Leponiemi, T. (2012). Matikka 3 Opettajan kirja, syksy. Helsinki: SanomaPro Oy.

Rinne, S., Salonen, M., Sintonen, A-M. \& Uus-Leponiemi, T. (2012). Matikka 5 Opettajan kirja, kevät. Helsinki: SanomaPro Oy. 